\title{
Safety Awareness Educational Topics for the Construction of Power Transmission Systems with Smart Grid Technologies
}

Brian Hubbard, Qian Huang, Patrick Caskey and Yang Wang, (Purdue University, USA)

\begin{abstract}
Power transmission facilities in the U.S. are undergoing a transformation due to the increased use of distributed generation sources such as wind and solar power. The current power grid system is also antiquated and in need of substantial retrofits to make it more efficient and reliable. The new energy transmission system being designed and built to optimize power delivery is known as "Smart Grid". The increased activity in the construction of power transmission facilities and installation of new technologies into the current power system raises potential safety concerns. Existing construction management curriculum may include general information about safety training, but does not typically include information about this specialized sector. The objective of this study was to work with industry to identify hazards and safety topics appropriate for inclusion in an introductory industrial construction course. These topics were subsequently developed and incorporated into a joint undergraduate and graduate course in industrial construction. A survey of the students was performed to determine the effectiveness of the course and to obtain feedback. This paper documents information on electrical system hazards and the results of the student surveys, both of which may be considered a first step in the exploration and development of a safety curriculum to meet the needs of the future.
\end{abstract}

Keywords: Electrical Safety, Electrocution, Smart Grid, Power Transmission, Safety Education

\section{Introduction}

Construction of high voltage electrical transmission and distribution systems in the United States is rapidly increasing. (EEI 2011) Workers constructing these electrical facilities encounter hazards common to all construction sites, as well as hazards unique to sites involving high voltage currents. The construction of high voltage electrical systems poses a number of hazards including electrocution and falls; these hazards may result in fatalities and injuries. In this study, voltages exceeding $10 \mathrm{kv}$ (10,000 volts) were considered high voltage installations. This reflects the range of common voltages for a substation used for power distribution to large industrial and commercial users in the United States (Durocher 2010). The purpose of this study is to determine the safety issues related to the construction of electrical transmission systems and the implementation of smart grid technologies. Construction hazards identified will be utilized in the development of educational modules for safety in an industrial construction course. A survey of the class where a portion of these concepts were implemented is presented.

\section{Background}

In recent years there has been increased construction activity in the power transmission sector (EEI 2011). The growth in this sector can be attributed to a number of factors, including:

- On-going Growth in Electricity Consumption: Electricity consumption has increased in recent years and projections forecast continued increases. Current and future energy demand in the U.S. requires new distribution substations and new power lines to 
connect new power sources to the power grid system to serve the increasing demand. The increase in expenditures on transmission and the distribution system over the last 3 decades has been dramatic, with an increase of over $35 \%$ from the 1980's to the 2000's (EEI 2011).

- Need for Rehabilitation of Existing Power Grid: The existing power grid system has exceeded its design life and much of the system includes outdated technology which requires reconditioning and replacement (ASCE 2011). Replacement system elements include components that can meet the increased capacities as well as components that employ new technologies such as smart grid capabilities. Smart Grid is a term used to define a transmission system that optimizes the power delivery with two-way communication between the producer and end user (DOE 2011) (Pratt 2010).

- New Energy Sources: New energy sources, including renewable "green" energy producing systems, such as wind and solar systems, are being implemented across the country. (Gellinges, 2009). These distributed energy sources often require new transmission and distribution systems. These systems are needed to connect the new power sources to the existing grid. Furthermore, the increase in the construction of new power generating sites requires an increase in the power carrying capacity of existing facilities.

The growth in the construction of transmission lines and associated power systems has created a need for an evaluation of the safety procedures in this sector. New workers in this sector will be either new to the construction industry, or from other sectors of the construction industry that have significantly different construction safety procedures. The construction workforce that transitions into the power sector from other construction sectors is not accustomed to working in the high voltage construction environment and may not be properly trained for safety in this area. In either case, the workers will not be well versed in the hazards and in appropriate hazard mitigation and safety protocol. Another consideration is that because new technologies are being implemented into these high voltage systems, there may be limited training materials available for workers and their employers.

The total number of fatalities in the power transmission and distribution industry in the U.S. is shown in Table 1 (BLS 2010). Based on the fatality statistics, approximately half of the fatalities over the last eight years can be attributed to "exposure to harmful substances or environments" which includes contact with electricity. The number of fatalities due to falls within the power transmission sector was very small over the last eight years, with many years without a fatality. In contrast, falls are the leading cause of fatalities for workers in the entire construction sector (OSHA 2012b). While this data represents those workers directly involved with power transmission and construction it does not account for the large number of deaths attributed to electrocution from workers outside the power transmission and distribution industry. For example, in 2010, 76 workers were killed due to contact with overhead power lines (BLS 2010). A better understanding of working around power transmission and distribution systems may have assisted in preventing these fatalities.

\section{Methodology}

The objective of this paper is to identify some of the safety needs of the power industry based on industry interviews and a review of regulatory requirements, identify how these needs can be translated into a curriculum for training, and evaluate the resulting safety training. 


\begin{tabular}{|c|c|c|c|c|c|}
\hline Year & $\begin{array}{c}\text { Total } \\
\text { Fatalities }\end{array}$ & $\begin{array}{l}\text { Transportation } \\
\text { Incidents }\end{array}$ & Falls & $\begin{array}{l}\text { Exposure to Harmful } \\
\text { Substances or } \\
\text { Environments }\end{array}$ & $\begin{array}{c}\text { Non- } \\
\text { Categorized }\end{array}$ \\
\hline 2010 & 14 & $\begin{array}{c}4 \\
(29 \%)\end{array}$ & & $\begin{array}{c}7 \\
(50 \%)\end{array}$ & 3 \\
\hline 2009 & 5 & & & $\begin{array}{c}3 \\
(60 \%)\end{array}$ & 2 \\
\hline 2008 & 21 & $\begin{array}{c}4 \\
(19 \%)\end{array}$ & & $\begin{array}{c}13 \\
(62 \%)\end{array}$ & 4 \\
\hline 2007 & 15 & & & $\begin{array}{c}7 \\
(47 \%)\end{array}$ & 8 \\
\hline 2006 & 19 & $\begin{array}{c}6 \\
(32 \%)\end{array}$ & $\begin{array}{c}4 \\
(21 \%)\end{array}$ & $\begin{array}{c}6 \\
(32 \%)\end{array}$ & 3 \\
\hline 2005 & 9 & $\begin{array}{c}3 \\
(33 \%)\end{array}$ & & $\begin{array}{c}4 \\
(44 \%)\end{array}$ & 2 \\
\hline 2004 & 25 & $\begin{array}{c}6 \\
(24 \%)\end{array}$ & $\begin{array}{c}4 \\
(16 \%)\end{array}$ & $\begin{array}{c}11 \\
(44 \%)\end{array}$ & 4 \\
\hline 2003 & 14 & $\begin{array}{c}5 \\
(36 \%)\end{array}$ & & $\begin{array}{c}5 \\
(36 \%)\end{array}$ & 4 \\
\hline Total & 122 & $\begin{array}{c}28 \\
(23 \%)\end{array}$ & $\begin{array}{c}8 \\
(7 \%)\end{array}$ & $\begin{array}{c}56 \\
(46 \%)\end{array}$ & 30 \\
\hline
\end{tabular}

Table1 United States Fatal Occupational Injuries for the Electric Power Transmission, Control, and Distribution Industry (BLS 2010)

\section{Interviews with Industry}

Meetings were held with three industry representatives to identify key areas where safety training was needed for electrical transmission and distribution. The interviews were intended not to provide a statistically valid sample of a large number of respondents, but rather to thoroughly investigate the issue through in-depth interviews. This approach was desirable because there are a limited number of large companies performing this work, which would make a statistically valid sample difficult to obtain. The three industry representatives consisted of an electrical contractor that specializes only in high voltage transmission line construction, an electrical contractor that provides a range of services to the construction industry including construction of sub stations for high voltage distribution (safety manager and two electricians), and a facilities owner/manager that utilizes high voltage power systems.

The main emphasis of the meetings were to determine 1) specific safety procedures for working with high voltage systems, 2) concerns regarding safety issues that need to be addressed, and 3) identify how new technologies such as smart grid systems may require additional safety procedures. While the results of these interviews may not translate to all contractors, they do provide a perspective, albeit limited, on the issues. The facilities owner provided a client perspective and also highlighted safety considerations associated with operation.

\section{Safety Information from Regulatory Agencies}

In addition to meeting with industry about construction hazards, a literature review was performed to determine the availability of regulatory requirements and safety information in the area of high voltage electrical construction. The literature review encompassed regulatory requirements in the United States, such as Occupational Safety and Health Administration (OSHA) standards, as well as availability of safety training material from other industry groups. 


\section{Identification of Construction Hazards}

Upon completion of the industry interviews and review of regulatory safety requirements, a list of critical safety hazards was developed that were unique to the construction of high voltage systems. The critical safety hazards will be the focus of future training for construction personnel who may be exposed to high voltage around electrical power transmission, distribution, and control systems.

\section{Results}

The results include the findings of the interviews and the review of regulatory requirements, both of which were used to identify appropriate safety awareness educational topics.

\section{Interviews}

Interviews provided substantial information regarding hazards and the safety procedures. Key hazards and safety concerns provide a glimpse into the power industry. Interviews were conducted with a facilities manager/owner overseeing electrical improvements on high voltage building systems, a safety manager and electricians who work on electrical substations, and a constructor of high voltage power transmission systems. Discussion includes example hazards for a specific application, as well as general construction topics that can affect safety, such as the contracting method, and an example best practice to improve safety.

Hazards of Retrofitting. Retrofitting presents hazards for high voltage buildings, substations and transmission lines. For high voltage buildings, retrofitting electrical systems provides unique hazards, due to both the dangers associated with the historic system, a potential lack of documentation regarding the historic system, and an environment that may be physically constrained in terms of workspace and space for the new equipment. As an example of the safety procedure used for retrofitting an electrical system to incorporate new technologies, the procedure to isolate a $12.5 \mathrm{kv}$ electrical feeder system in order to install updated transformers and switchgear with advanced communication technologies was reviewed. The work procedure had both construction details and safety practices noted. The procedure required multiple managerial and safety supervisor approvals before work could be started. These approvals were required to ensure that the procedure provided adequate safety for the worker.

A discussion of the work procedure highlighted the dangers of working with old high voltage systems; old systems lack safety devices that are common on new equipment. This is illustrated by the electrical vault for power distribution that workers would have to enter, as shown in Figure 1. When working in this facility, there is a high risk of electrocution by contact due to the exposed electrical contacts. The older systems also pose a threat when activating/deactivating switches. This operation has to be completed while the system is electrified or "live". This live line work requires an electrical construction technique known as "hot sticking" to be utilized. In this method, work is done utilizing insulated tools. The worker is separated from the energized circuit by the insulated tool (Chan 2004). Even if properly insulated, the worker always has to be aware of the potential for arc flash when working on live high voltage systems. The worker may be required to wear additional personal protective equipment (PPE) such as an arc flash suit or use an arc suppression blanket (electrical blast blanket). An example of an arc flash suit with insulated electrical gloves is shown in Figure 2. This kind of suit is important in the power sector of the construction industry, but is not commonly used in other construction sectors. 


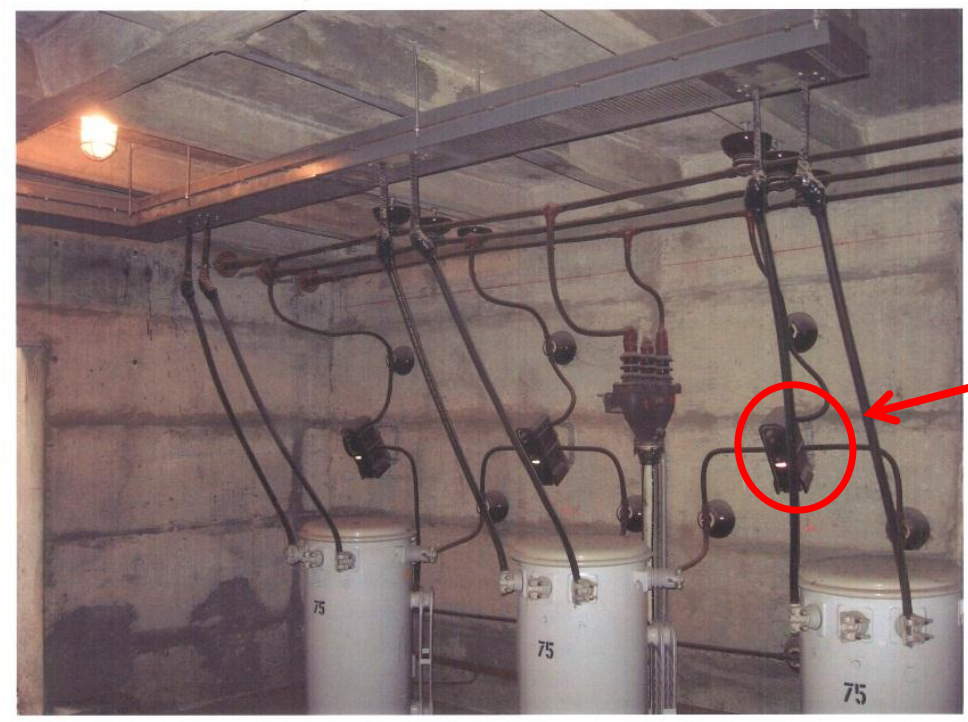

Exposed electrical contacts are an electrocution hazard near switch.

Figure 1 Outdated Electrical Vault with Switchgear and Transformers

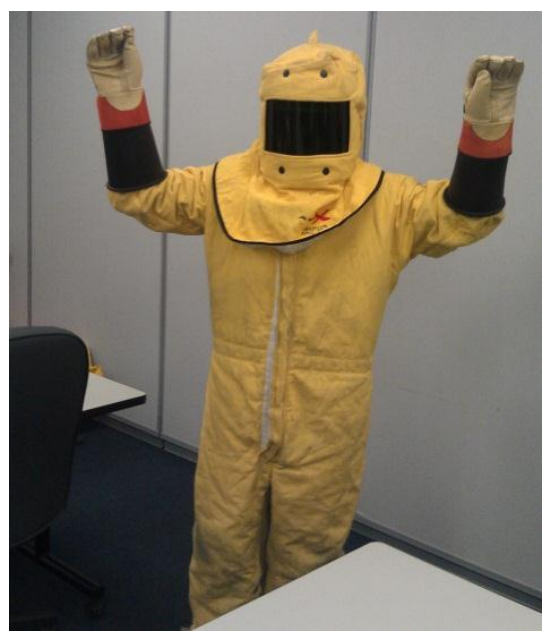

Suit provides full body and face protection. This personal protection equipment is rarely seen in other construction sectors.

Figure 2 Example of Arc Flash Suit with Insulated Electrical Gloves

Electrical Hazards for All Workers. A major concern is not just the safety of electricians, but also the potential hazard of high voltage electrical construction for workers from other trades working near high voltage equipment. Workers in the electrical trades not only have the training, but also typically have the appropriate personal protection equipment (PPE), such as that shown in Figure 2; however, workers trained in other trades, such as carpenters, plumbers, labourers, may not understand the risks, or be wearing the PPE necessary when working in close proximity to high voltage lines. This concern points to the need to ensure that workers in all trades have a comprehensive understanding of the risks associated with working around high voltage systems.

Figure 3 shows the electrical vault after improvements have been made to the system. The advanced electrical equipment is much more protected and allows for worker access into the room without them being at risk. The new system is an excellent example of how electrical system hazards can be mitigated through the design of new systems. This system presents minimal risk to nearby workers. 


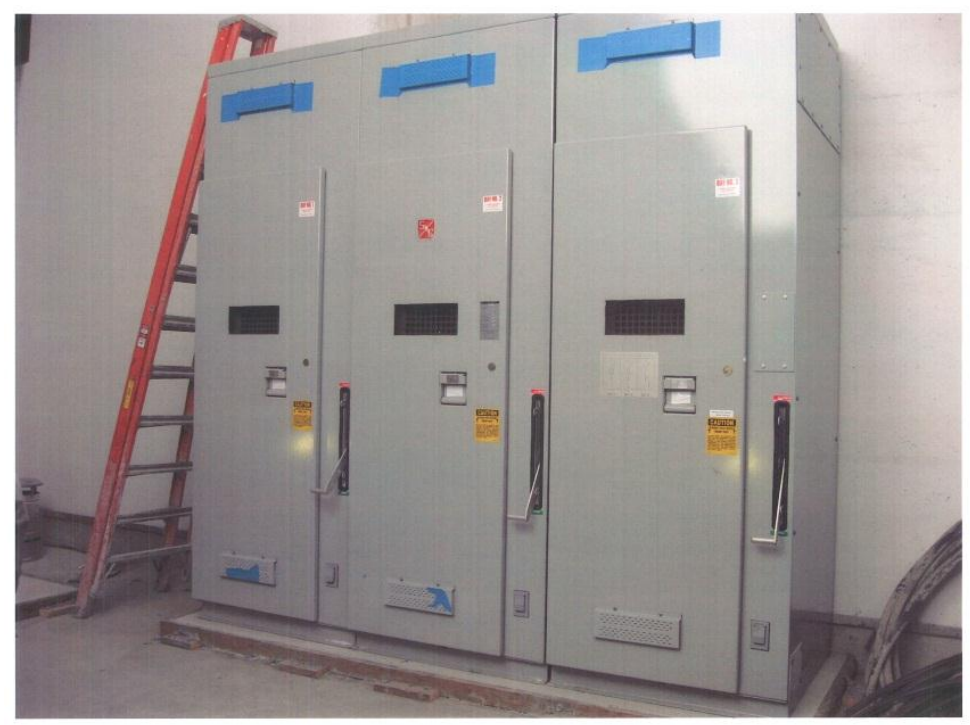

Advanced technology

switchgear and

transformers allow system

to be controlled remotely for

increased safety.

Figure 3 Electrical Vault with Advanced Technology Switchgear and Transformers

Substation Hazards. Electrical substations are used to either step down the voltage of a transmission system so it can be distributed to customers or step-up voltage from power generation systems so that it can be efficiently transported on the transmission power lines. There has been increased construction of substations that step-up the voltage in order to provide transmission facilities for new energy sources. These new energy sources, such as wind and solar power, require that the voltage be stepped up to accommodate the high voltage transmission requirements. There is also significant reconstruction work being done on replace existing equipment in substations, such as the installation of new smart grid technologies, and upgrades to increase capacity to accommodate green energy sources.

High Voltage Transmission Line Construction. These systems consist of erecting the tower for the conductors, stringing the conductor wires, and connecting the conductor wires at power sources and distribution substations for step down voltage conversion. Additional new technologies to optimize the power efficiency of the grid that are being added and include: fiber optic cables for communication, wireless high voltage switches, and meteorological equipment for sensing oncoming weather issues (Brandt 2011). The process of constructing these transmission systems is a specialized field of construction and the market is dominated by a few firms. The equipment used for the stringing operation is typically custom built for the contractor based on their specifications, and is considered proprietary. The main safety concerns for the contractor focus on power lines that are not in service; although these power lines do not carry a live current, they can become energized by existing systems through either induced voltage or inadvertent contact with a live line.

In the U.S., it is difficult to obtain right-of-ways for new power transmission lines. When transmission lines are improved and the voltage of the system is increased, the power transmission authority (typically the Regional Transmission Organization, RTO) often expands the right-of-way of an existing system, which is typically more cost effective than buying new property for the lines. As a result, new systems are often built on or near existing lines, which presents hazards. Many of these existing transmission systems cannot be deenergized during the rebuilding process because the transmission system is at capacity with very little redundancy (DOE 2011). Power transmission line contractors will therefore build over the top of and around an existing energized system.

Hubbard, B et al (2013) 'Safety awareness educational topics for the construction of power transmission systems with smart grid technologies', Australasian Journal of Construction Economics and Building, 13 (3) 114-127 
Voltage Induction Hazard. One hazard associated with electrical work is voltage induction. This is a hazard for many circumstances. For substations, hazards are often amplified because the substations are constantly being made smaller to reduce the footprint. For existing facilities, additional equipment is being added within the existing footprint, increasing the density of live electrical components. Both of these situations reduce the distances between high voltage equipment. The distance between components is an important consideration, because each piece of energized electrical equipment has a significant electromagnetic field around it that may induce voltage into other systems; this is referred to as voltage induction. In high voltage applications, the voltage induction may be high enough to cause injuries and even fatalities. To reduce these risks, special care must be taken to ground equipment and provide safe working distances (OSHA 2012).

Voltage induction is also a hazard for high voltage transmission line construction. When stringing the new power lines, the conductor may pick up voltage from the neighbouring existing lines either through induction or inadvertent contact between the de-energized line and an energized power line. Both of these hazards are difficult to prevent when working with transmission lines carrying $345 \mathrm{kv}$ to $750 \mathrm{kv}$. The proprietary conductor stringing equipment used by these contractors all have significant capabilities to ground the wire they are stringing; this helps reduce the likelihood that the conductor will be energized during the stringing process.

Safety Challenge: Design Build Contracting. The construction contracting process can impact the safety of a construction project, in this case, substation construction. In Design Build contracting, the design is often done in tandem with the construction process. This makes it more difficult to formulate a strong construction site safety plan, since the design is evolving. On-going safety planning and effective communication is necessary to counter this.

Best practice: Job Hazard Analysis (JHA) Updates. One way to increase safety on any project is through the use of current JHA updates. One company has a policy to review the hazards of the construction site in the morning prior to the commencement of the day's work. During that time, a written job hazard analysis is provided to the worker. It should be acknowledged, however, that changes on the construction site may affect the JHA. This is especially true for construction projects that have a tight schedule due to an electrical outage. In these situations, the job hazards may be very dynamic, and change throughout the day. In this case, the JHA must be constantly modified to reflect the changing circumstances and hazards that result from a dynamic construction site. The timely updating of JHAs and effectively communicating changes to the JHA is a critical feature of a safety program.

\section{Safety Information from Regulatory Agencies}

The Occupational and Safety Health Administration (OSHA) provides the primary regulation for worker safety in the United States. While some states have their own state OSHA, these agencies typically mirror many of the requirements of OSHA. OSHA compiles data regarding occupational injuries and fatalities, by sector and by cause, and provides information to mitigate worker risk. Electrocution is one of four construction hazards that OSHA has identified as a target area in which to focus specific training, due to the number of fatalities and injuries (OSHA Training Institute 2011). OSHA has developed material for courses for both the standard OSHA 10 hour course and OSHA 30 hour course; however, this material is focused on general electrical procedures and does not provide significant details for high voltage construction.

Although not included as a standard OSHA module, there is information available. The "OSHA Safety and Health Regulations for Construction" provides information for working on power transmission and distribution; this information is comprehensive and covers many of the hazards discussed (OSHA 2012). As an example, a minimum clear distance to perform a

Hubbard, B et al (2013) 'Safety awareness educational topics for the construction of power transmission systems with smart grid technologies', Australasian Journal of Construction Economics and Building, 13 (3) 114-127 
"hot stick" operation is provided for power lines from $2.1 \mathrm{kv}$ to $765 \mathrm{kv}$. The dangers of hot stick operations were mentioned in interview 1.

Another resource for safely working in high voltage transmission systems is "Live Work Guide for Substations", a resource developed by Electric Power Research Institute (EPRI) (Chan 2004). This guide is a comprehensive training manual for working on live high voltage power systems. It provides details on developing a work plan for working on live power systems, including development of JHAs, different methods for live line work, minimum approach distances for both qualified and non-qualifies workers, identification of appropriate PPE, and voltage induction hazard identification.

For the implementation of smart grid technologies, there is little safety training information available since this is a new area of the construction field. Furthermore, not all documents on the smart grid provide comprehensive information for high voltage applications. For example, a smart grid technician training guide recently written provided electrical safety hazard and PPE information, however, it did not provide extensive details on working around high voltage systems (Freeman 2010).

\section{Safety Awareness Educational Topics}

Based on the results of the interviews and the safety information from regulatory agencies, a series of topics was developed for a basic course in industrial construction. These topics are suitable for presentation to students to raise their awareness of the hazards of working around high voltage systems. Major topic areas include: 1) unique aspects of working around high voltage systems, 2) live power line work, 3) voltage induction hazards, and 4) managing a changing safety environment in a compressed construction schedule.

1. High Voltage Systems: Course material was developed to provide an introduction of how high voltage systems operate and concepts behind smart grid technologies. The step-by-step procedure to construct a high voltage transmission system is included in the course instruction. The construction operations include constructing the towers and stringing the conductors. Safety procedures are provided for each stage of the operation.

2. Live Power Line Work: A majority of the power grid construction is done either on live lines or in close proximity to live lines, which was reflected in the course material. Procedures for working on a live line are provided, along with details of the required specialized PPE and construction equipment. A review of OSHA regulations for working on high voltage systems is also included.

3. Voltage Induction: Understanding concepts related to how a de-energized line can be energized by induced voltage from electromagnetic fields from energized lines and equipment is critical for working safely in a high voltage environment. The procedures to protect workers and equipment from this hazard are included in the course instruction.

4. Managing a Changing Safety Environment in a Compressed Construction Schedule: The construction of electrical systems is typically conducted during short power outages. Some of these outages may be planned in advance and others may be the result of an emergency shutdown. In either case, the construction process for these systems is typically fast paced and very schedule driven. Working in this environment requires constant attention to safety. On-going reviews of the current job hazards must be conducted throughout the day as the job site and conditions change. In some cases, design changes may occur during a project, particularly during design build; these design changes may warrant modification of the JHA.

Hubbard, B et al (2013) 'Safety awareness educational topics for the construction of power transmission systems with smart grid technologies', Australasian Journal of Construction Economics and Building, 13 (3) 114-127 


\section{Course Content Development and Survey}

A course was developed to serve as an introduction to the cutting-edge smart grid technologies. This course covers several interdependent areas, including power generation, energy transmission, distribution and storage, and economic policies associated with the smart grid power systems. All of these areas also addressed specific power distribution worker safety.

The first course module is an overview of the current power transmission system and basic smart grid technologies. The drawbacks of existing U.S. power grid systems are discussed along with concepts such as reliability and vulnerability, lack of end-user energy management, and two-way communication issues across the power grid are addressed. Next, the concept and definition of smart grid are elaborated, including key factors and characteristics of the smart grid. This course module is expected to deliver a comprehensive comparison between traditional power grid systems and smart grid power systems.

The second course module focuses on energy generation, distribution and storage. Since one of the important characteristics in smart grid systems is distributed energy generation, which involves multiple heterogeneous energy generation approaches (such as solar cells, wind turbines, micro-turbine generators, thermoelectric generator and fuel cells), lower the energy cost and enhance the grid reliability. Next, a review of several potential renewable energy sources is provided, including solar, wind and hydro energy generation. The module is finally concluded with a discussion on emerging technologies of energy storage with their technical challenges and trend.

The content of power grid basics and transmission line stringing methods are covered in the third module. Grid line monitoring techniques are discussed with a focus on reliability and security concerns. Superconductor based transmission line design is also introduced, because superconductors are an attractive and feasible material for the transmission line of the future. A major component of this module is the safety technique of live power line work and the associated techniques. Voltage induction was also covered under live line working because this is a common safety issue when dealing with transmission line stringing.

In order to ensure a successful implementation of smart grid technologies, the strategies and policies of U.S. power transmission systems need to be understood. Therefore, economic assessment and policies are introduced in the fourth educational module. The main reference is a report from the executive office of the President of the United States (Chopra et al. 2011). This report provides an in depth look at national policies for future Smart Grid technologies in U.S. Economic factors and considerations for implementation of smart grid systems are also discussed in this module.

\section{Survey Data Analysis}

The survey included 21 questions focused on several key smart grid concepts including: smart grid course information, benefits of smart grid technology, possible challenges of smart grid technology, and personal interest in smart grid technology.

The first six questions addressed the smart grid course information. In response to the statement, "When signing up for this class was your interest in high voltage transmission and smart grid concepts what attracted you to this class", 33\% agreed. Fifty percent agreed with the statement, "After graduation are you planning on working with a firm that is actively involved with high voltage transmission/smart grid projects". In addition, 33 percent thought that they are highly likely to work on high voltage transmission/smart grid projects.

Two background knowledge related questions were assigned. Seventy-five percent agreed with the statement, "You had little knowledge of smart grid, except for some basic idea and/or definitions". The remaining $25 \%$ of respondents had no knowledge of smart grid

Hubbard, B et al (2013) 'Safety awareness educational topics for the construction of power transmission systems with smart grid technologies', Australasian Journal of Construction Economics and Building, 13 (3) 114-127 
concepts before attending this class. Of all the respondents, the ways they obtained the information on smart grid technologies were from media reports, topics from other general courses, and working experience from related projects. No participants had prior knowledge from a specific course or training module on smart grid technology. These results provided evidence to justify the need for developing a specific course that focuses on the construction of high voltage electric transmission systems and implementation of smart grid systems.

Figure 4 illustrates the topics identified as most helpful. The majority of students who completed this survey reported that distributed generation, power grid basics, and grid monitoring are most important over other topics. In addition, no respondents believe that superconductors and distributed energy resource are important.

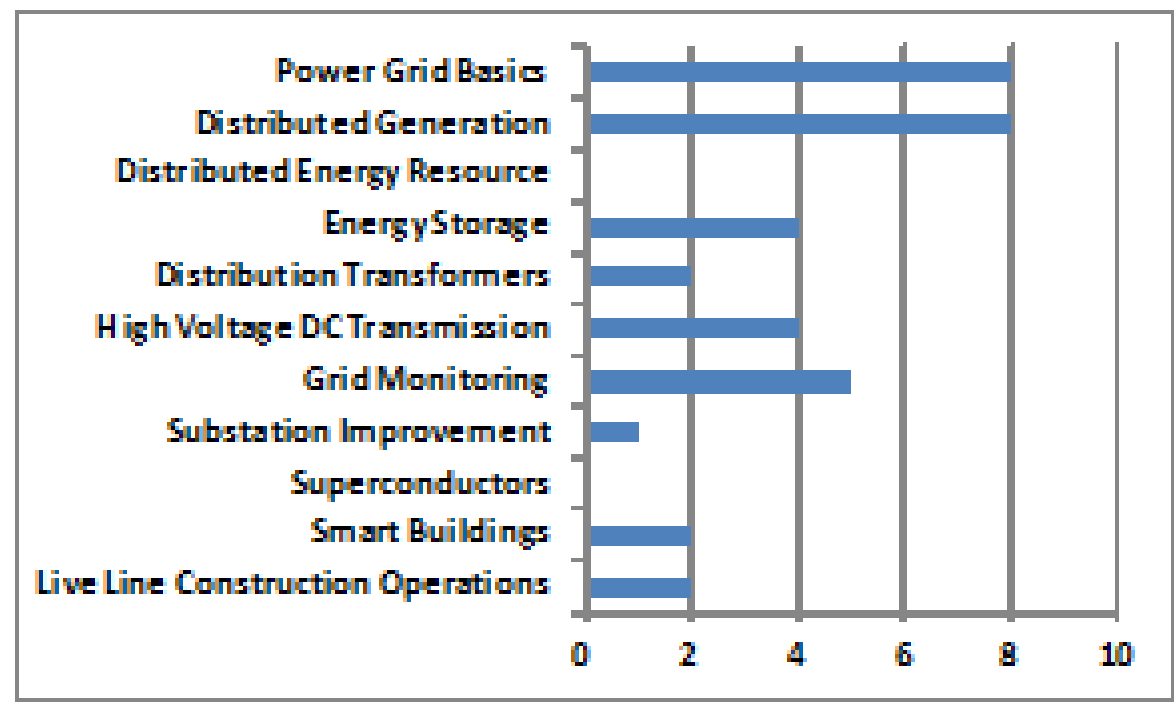

Figure 4 Survey results, list three important topics you learned from this course

The respondents also identified topics that they did not think would be used, as illustrated in Figure 5. Superconductors, distribution transformers, smart buildings and live line construction operations are not expected to be used. All respondents agree that power grid basics will be significantly used in industrial workplace and is is important for their education.

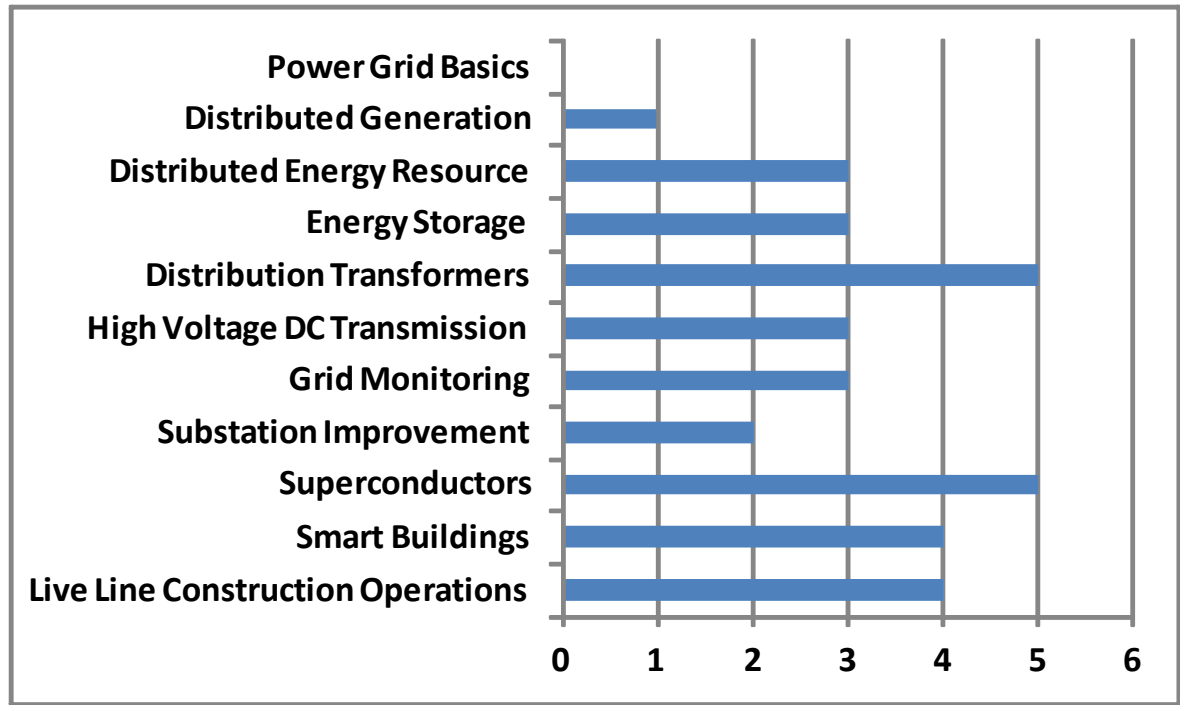

Figure 5 Survey results, list three topics you believe you will not use

Of the 21 total survey questions, 15 questions used the five-point Likert-type scale (Burt 2003). The response choices of these 15 questions are "strongly disagree", "disagree", "not applicable", "agree", and "strongly agree". Scores from 1 to 5 are assigned to responses

Hubbard, B et al (2013) 'Safety awareness educational topics for the construction of power transmission systems with smart grid technologies', Australasian Journal of Construction Economics and Building, 13 (3) 114-127 
from "strongly disagree" to "strongly agree". The 15 questions and mean response for each question are shown in Table 2. The mean response of all these questions is 3.85, which implies the average response is "agree". The mean response for questions 7 and 8 are less than 3, which indicates the participants do not have interest to do research in smart grid area. Referring to the question 15, all respondents agree that they are more likely to accept smart grid technology based on what they have learned in this class.

\begin{tabular}{|l|c|}
\hline \multicolumn{1}{|c|}{ Survey Questions } & $\begin{array}{c}\text { Mean } \\
\text { Response }\end{array}$ \\
\hline (1) I am interested in learning about smart grid technology & 4.33 \\
\hline $\begin{array}{l}\text { (2) I am interested in learning about the societal advantages of smart grid } \\
\text { technology }\end{array}$ & 4.42 \\
\hline (3) I have access to adequate amount information about smart grid technology & 4 \\
\hline (4) I am interested in learning about smart grid technology privacy policies & 4.08 \\
\hline (5) I am interested in learing about smart grid technology security policies & 4.08 \\
\hline (6) I am interested in pursuing further studies in an area related to smart grid \\
technology
\end{tabular}

Table 2 Survey Questions and Mean Response

Statistical methods were also used to analyse the survey data, specifically the block design approach. In this approach, different features are the interested factor, while the student factor is a nuisance factor that is measurable and controllable but not of interest. The hypothesis was that at least one of the features attracts more interest of the student. Then, the null hypothesis is that the students place equal interest on each of the fifteen features of smart grid technology. To test the hypothesis, a two-way ANOVA (Analysis of Variance) was used in this block design survey (Burt 2003). There are several assumptions put forward for this model, which include: (1) there is no interaction between treatment effect and block effect (2) errors are independent and normally distributed and variance should be constant. These assumptions will be proved and verified using the survey data. The statistical software named Statistical Analysis System (SAS) was used to performance the diagnostics and verification.

ANOVA compares the means of different question responses by using F-test approach. If the null hypothesis in this study was rejected, it indicates the difference of means among 15 questions is significant, and hence some of the topics gain more interest from the survey participants. According to statistics theory, $p$-value in F-test refers to the probability that the test statistic is larger than or equal to the observed statistic when the null hypothesis is true. The SAS results of the two-way ANOVA are shown in Figure 6. In this figure, since p-value (less than 0.0001 in Figure 3 ) is smaller than a significant small level (usually 0.05 used), null hypothesis should be rejected and our hypothesis is valid. The truth behind the survey data is some topics gain more interest from the survey participants.

Hubbard, B et al (2013) 'Safety awareness educational topics for the construction of power transmission systems with smart grid technologies', Australasian Journal of Construction Economics and Building, 13 (3) 114-127 


\begin{tabular}{|c|c|c|c|c|c|}
\hline \multicolumn{6}{|c|}{$\begin{array}{l}\text { Analysis of student's interest in smart grid technology } \\
\qquad 15: 33 \text { Sunday, May } 27,2012\end{array}$} \\
\hline \multicolumn{6}{|c|}{$\begin{array}{l}\text { The GLM Procedure } \\
\text { Dependent Variable: response }\end{array}$} \\
\hline Source & DF S & Sum of Squares & Mean Square & F Value & $\operatorname{Pr}>F$ \\
\hline Model & 25 & 107.1166667 & 4.2846667 & 5.51 & $<.0001$ \\
\hline Error & 154 & 119.8333333 & 0.7781385 & & \\
\hline Corrected Total & 179 & 226.9500000 & & & -value \\
\hline $\begin{array}{ll}\text { R-Square } & \text { Coe } \\
0.471984 & 22.5\end{array}$ & $\begin{array}{l}\text { fVar } \\
1225\end{array}$ & $\begin{array}{l}\text { Root MSE } \\
0.882122\end{array}$ & $\begin{array}{l}\text { response Mean } \\
3.850000\end{array}$ & & \\
\hline
\end{tabular}

Figure 6 Results of ANOVA procedure to test the hypothesis

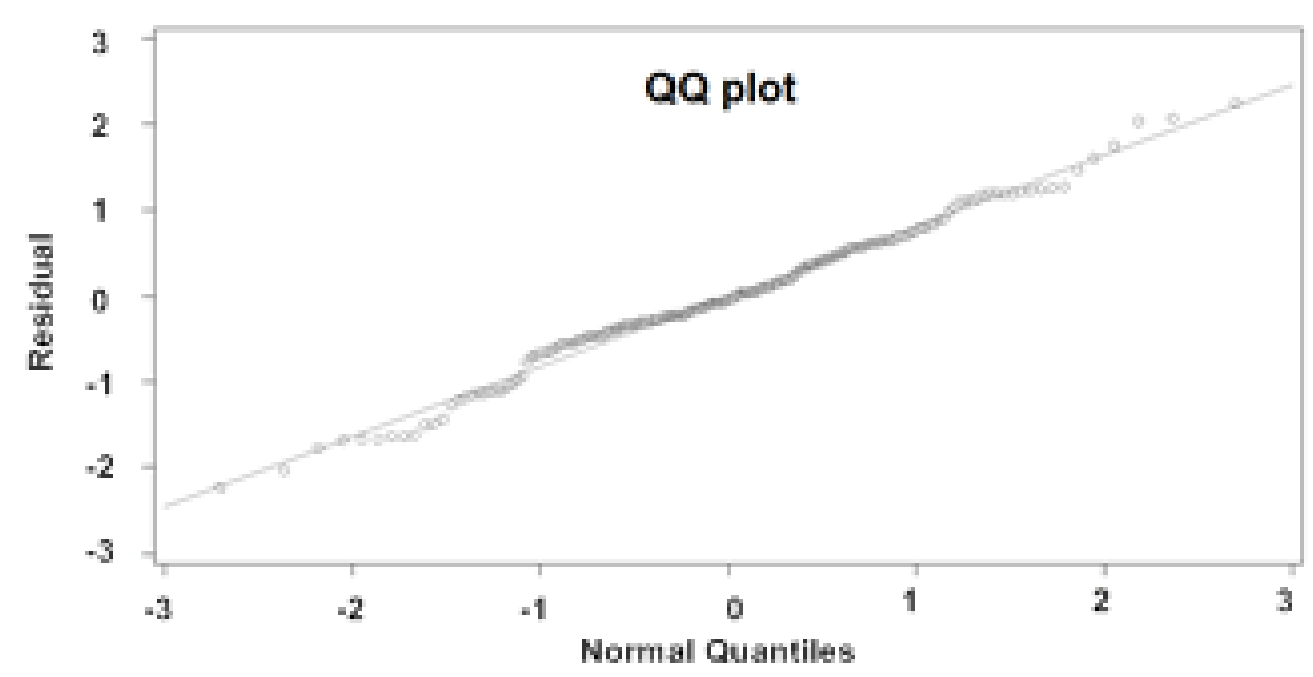

Figure $7 \mathrm{QQ}$ plot for verification of assumption about normality and consistency

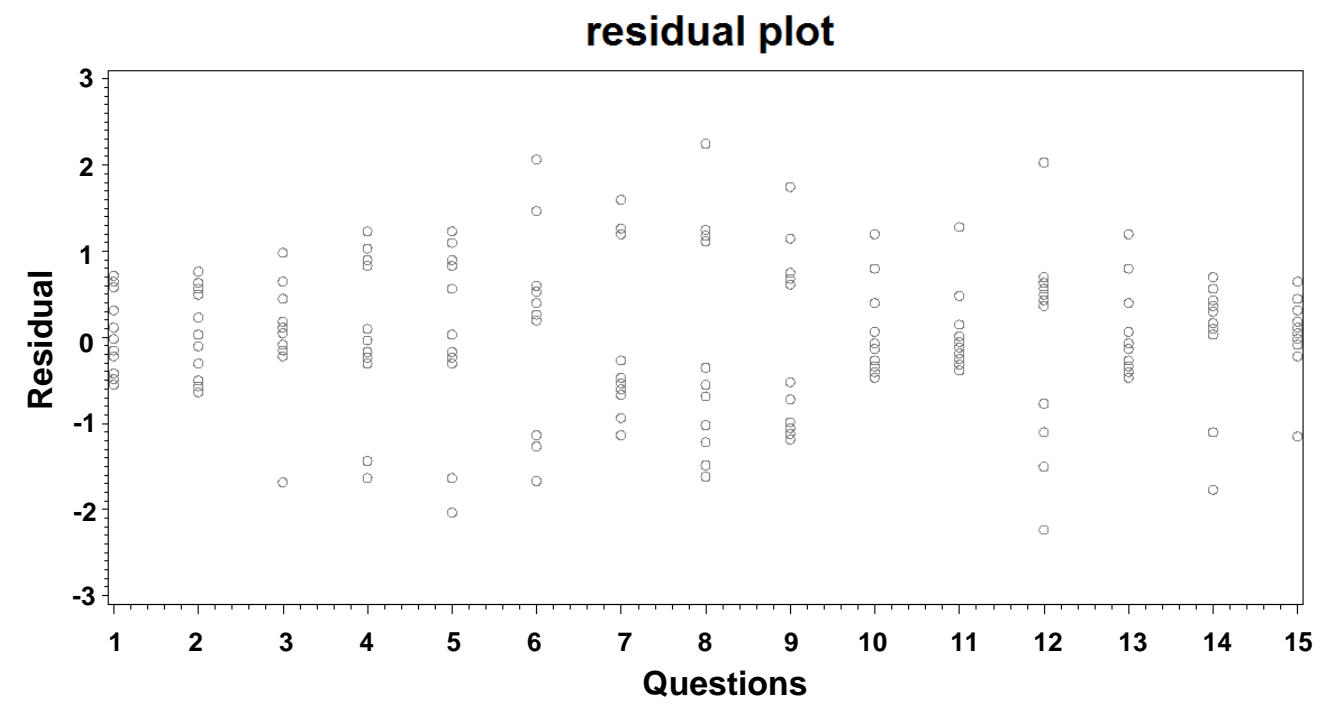

Figure 8 Residual plots for verification of independent observations

Hubbard, B et al (2013) 'Safety awareness educational topics for the construction of power transmission systems with smart grid technologies', Australasian Journal of Construction Economics and Building, 13 (3) 114-127 
The last statistical analysis performed was to determine the topics that were most interesting to the students among the fifteen survey questions. A box plot was employed in this study. From the box plot (Figure 9), the response scores for questions 1, 2, 4, 5, 10 and 13 are more than 4 . These six questions are closely related with the interest of students on learning knowledge about smart grid technology and using smart grid technology. The response scores for questions $6,7,8$ and 9 are less than 4 . These four questions are more related with the interest of students on being a professional or researcher in smart grid area. It is easy to observe from Figure 9 that the students have more intention to focus on industrial smart grid concepts rather than focusing on research in smart grid areas.

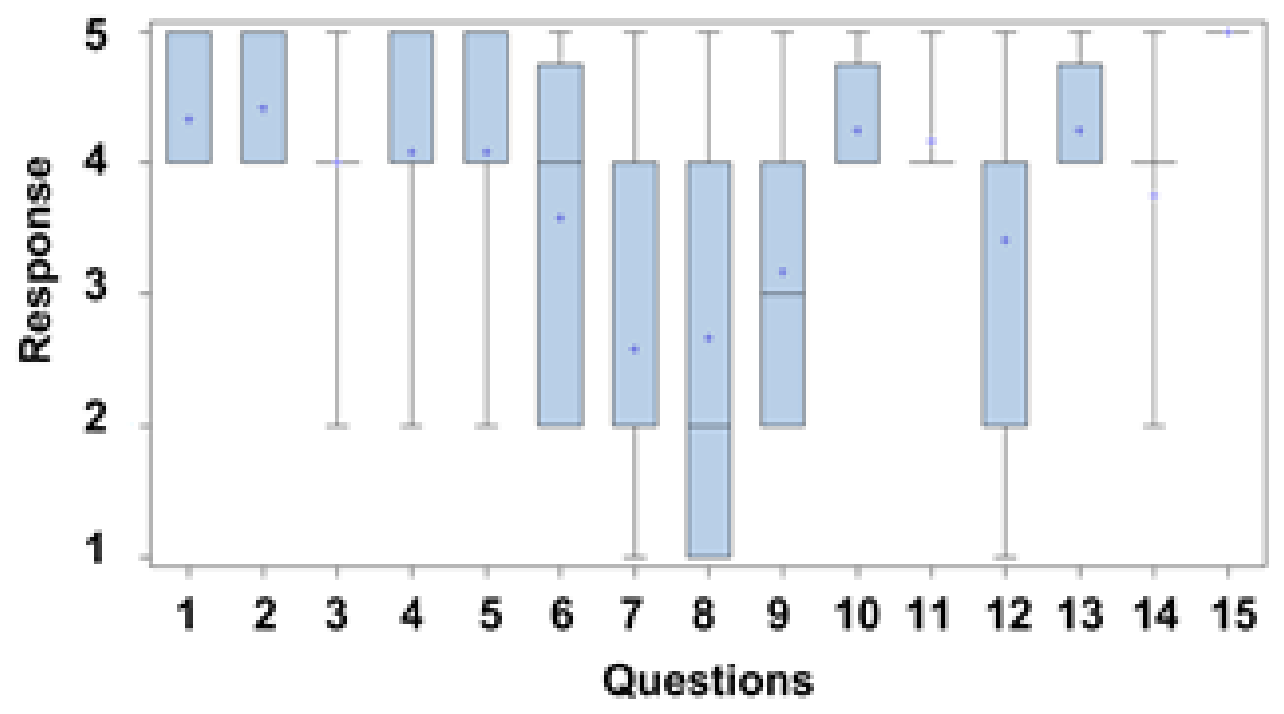

Figure 9 Analysis of student's interest in smart grid technology

\section{Conclusion}

In the United States, construction in power transmission and distribution systems is expected to be a growing sector. The many workers involved in this enormous undertaking will need to be well versed in the safety hazards involved in high voltage construction operations. This paper provides an initial identification of the kind of safety topics that new employees in this sector need to be aware of, identifies topics that may be appropriate for inclusion in an introductory industrial construction course covering construction safety of power transmission, distribution and control, and provides an evaluation of these topics from the student perspective. Additional research to more thoroughly document the safety issues and develop detailed safety curriculum to address these issues is recommended. Another area that needs to be more fully developed is the responsibility and training for supervisory personnel when workers are working on or near live electrical systems. Historically, the construction industry has proven itself very responsive to the market forces. The industry must also work to assure that the safety protocol is equally responsive to the needs of the workers.

\section{Acknowledgements}

This research study was partially supported by a U.S. Department of Energy Crossroads Smart Grid Workforce Development Program Grant.

\section{References}

ASCE, 2011, Failure to Act, The economic impact of current Investment Trends in Electricity Infrastructure, ASCE, Reston, VA.

Bureau of Labor Statistics (BLS) 2010, 'Fatal occupational injuries by industry and event or exposure', United States. Bureau of Labor Statistics. http://www.bls.gov/iif/oshcfoi1.htm, April 15, 2012. 
Brandt, C. 2011, 'Lineman Deploy Smart Grid Technology', Transmission and Distribution World, 63 (9) 64N - 64Q.

Burt, R. 2003, The factors influencing a construction graduate in deciding upon their future employer, Journal of Construction Education, 8 (2), 94-100.

Chan, J. 2004, Live Work Guide for Substations, EPRI, Palo Alto, CA.

Chopra, A., Kundra, V. \& Weiser, P. 2011, 'A policy framework for the 21st century grid: enabling our secure energy future', Report, Executive Office of the President of the United States, June, 2011.

Department of Energy (DOE) 2011, 'What a Smart Grid Means to Our Nation's Future', http://energy.gov/sites/prod/files/oeprod/DocumentsandMedia/Policymakers.pdf, April 2, 2012.

Durocher, D. 2010, 'Considerations in Unit Substation Design to Optimize Reliability and Electrical Workplace Safety', 2010 Industrial \& Commercial Power Systems Technical Conference, Tallahassee, FL.

EEI 2011, EEI Statistical Yearbook/2010, Edison Electric Institute, Washington, D.C., http://www.eei.org/whatwedo/DataAnalysis/IndustryData/Documents/TransmissionInvestment-Expenditures.pdf April 2, 2012.

Freeman, W.G. 2010, Smart Grid Technicians Training Guide, Educational Technologies Group, Richland, WA.

Gellinges, C. W. 2009. The smart grid: enabling energy efficiency and demand response, CRC Press, 1st edition, August 21, 2009.

OSHA 2012, Safety and Health Regulations for Construction 1926.950, Occupational Safety and Health Administration, Washington, D.C.

http://www.osha.gov/pls/oshaweb/owadisp.show document?p table=STANDARDS\&p id=1 0821 April 10, 2012.

OSHA 2012b, Fall Protection, Occupational Safety and Health Administration, Washington, D.C.

http://www.osha.gov/doc/outreachtraining/htmlfiles/subpartm.html April 15, 2012.

OSHA Training Institute 2011, Construction Focus Four: Electrocution Hazards, OSHA Directorate of Training and Education, Washington, D.C.

Pratt, R. G. 2010, The smart grid: an estimation of the energy and CO2 benefits, Pacific Northwest National Laboratory, Washington, www.pnl.gov/main/publications/external/technical reports/PNNL-19112.pdf 